\section{Being a patient party}

\section{Shrestha A}

Intern, Kathmandu Medical College, Sinamangal, Nepal

\begin{abstract}
A s a medical student, we spend many hours of our clinical teaching asking questions during history taking and examining the patient. When we go to wards, we scan the cardex and find out the new cases that we have. This is contrary to the ideal way suggested by our professors of going to a new patient and asking history. In the next minute what we do is, we go in, introduce ourselves and ask questions under the headings of the history. This usually pertains to the diagnosis we already knew and few other differential diagnoses. Finally we say "thank you" and walk away swiftly from the patient amongst the bunch of non history takers wondering what's going to be the questions asked during the case presentation (this is the usual case scenario but not always).
\end{abstract}

But do we actually have time thinking more about the patient and patient's party? Except that patient agreed or declined to give history, the whereabouts of the patient and patient party rarely crosses our mind. This usually happens unless they appear different than we generally encounter. These things exactly used to happen with me and amongst most of my friends.

Now, let the usual situation change, let's flip side. Here you are the patient party and have admitted someone in a ward for an operation. Then the story is begeted from different perspective. This is what I perceived when I got my mother admitted for the operation for fibroids. It was something different than what I would perceive as the usual medical student.

After the ordeal of my final year MBBS examination, I had various plans for the vacation. Unlike planned, I got a call from home that mom is ill. So I called her to the hospital and got her checked by a consultant Gynaecologist. She immediately suggested an operation. My mother had been previously on medications. As the doctor had to leave for London after 4 days, surgery was planned 3 days later. Fortunately or unfortunately the day was to be a holiday (martyrs day) so she end up suggesting surgery 2 days later, 1 day earlier than planned. I complied, but surgery on such haste, how good would that have be? I question it now. Many things had to be managed in short time. I got my mother admitted in the afternoon of the next day in the general ward. After financial arrangement I bought medicines, listened to what doctors suggestions and stood by my mother's side most of the time. I got acquainted with some of the other patients in the ward, up-close. One patient was post operative case of Vesico-vaginal fistula (VVF) repair and the other one planned for vaginal hysterectomy and pelvic floor repair. One patient was planned for operation for fibroids but was waiting for the correction of anaemia. I spoke to many of them. Most of them seemed happy with the service yet some complained about the little time the doctors spend with them. To my surprise the patient with VVF had been there for 33 days (operated after 15 days of admission and planned on catheter for 4 weeks, but just past 18 days post operation) and no money left for treatment. Not even for the return tickets to their hometown Sindhuli. What a plight that had be. The next day was the day of surgery. I recall the day vividly. I was extremely busy, rushing to pharmacy getting drugs and responding to the immediate changes of plans during the surgery. The duration of the surgery took little longer than usual, adding further to my worries.

While surgery went on, I was waiting with my fingers crossed. I was constantly concerned about how the surgery was going on inside. The emotional swing was large. I was so anxious that every time the attendant came out, I queried him how was the surgery going on. I might have irked him. I was relived, when 15 minutes before the completion of the operation the anaesthetist came out and hinted me everything is fine in there. How had the patient party felt in such a situation? Their anxiety level must have soared high to qualify for the solid consolation. Every word the attendant and surgeons speaks is listened with all ears. I was allowed in moments after the operation was over. Mother was still dozing off the sedative and could barely speak. I

\section{Correspondence}

Dr. Anup Shrestha

Intern

Kathmandu Medical College, Sinamangal, Nepal

E-mail: shresthaanup2001@hotmail.com 
anticipated her to be fine now on, and as thought she has been doing fine ever since. I know myself how grateful I am to the surgeons and God as well. Are the human emotions always in human control? Probably not. This is one of few such moments. Probably praying is all that can be done on such a situation, besides emotional backup. As the famous hindi saying says: "aapko duaa ki jaaroorat hain dabaon ka nahin"( u need prayers not the medicine).

I also ponder now how would a naïve patient party have dealt in such a rush hour. For me, I was privileged to have my education there. Sorting out whereabouts inside the hospital was an easy for me. Identifying the laboratory, paying the bills and getting advises from seniors and else. But how would it have been for a completely new stranger, especially in the situation where decisions changes. It's demanding.

Surgery in such haste was a lifetime experience for me. And moreover surgery on someone who is the nearest and dearest, it is another challenge. More when you are surrounded by the immature friends who have yet to venture the long path of experiences of realities and hardships of life.
The whole event was illuminating in itself, in the sense that the knowledge we read in our medical textbooks pertaining to outcomes of any interventions is not making the sole impact on patient's health. His socioenomic status, affordability, knowledge and preparedness for any event are equally important too. Good acknowledgement of the patient parties with the situations like this is also essential. These are few things that we skip during our ward classes. All words that the doctors speak before and during the surgery should be weighed for pros and cons. Taking a few minutes of our time and reinforcing the morale of the patient party definitively bolster their confidence. Talking to patient and the patient party in the wards, sharing with them few experiences might mitigate their anticipatory anxiety. Things like this make us more humane in this hassle of life. This is what we meant to be as doctors, to care for the patient and the patient party. And this is might be one aspect of what we talk as a holistic approach to the patient. 